\title{
Cardinal Henri de Lubac, La Rencontre du bouddhisme
} et de l'Occident

Paris, Cerf, 2000, 350 p., (traductions, errata, glossaire, index) (in Oeuvres complètes, XXII, Sixième section)

\section{Frédéric Lenoir}

\section{(2) OpenEdition}

\section{Journals}

Édition électronique

URL : http://journals.openedition.org/assr/487

DOI : $10.4000 /$ assr. 487

ISSN : $1777-5825$

Éditeur

Éditions de l'EHESS

Édition imprimée

Date de publication : 2 octobre 2001

Pagination : 93-156

ISBN : 2-222-96712-0

ISSN : 0335-5985

Référence électronique

Frédéric Lenoir, "Cardinal Henri de Lubac, La Rencontre du bouddhisme et de l'Occident », Archives de sciences sociales des religions [En ligne], 116 | octobre - décembre 2001, document 116.29, mis en ligne le 11 octobre 2005, consulté le 24 septembre 2020. URL : http://journals.openedition.org/assr/487 ; DOI : https://doi.org/10.4000/assr.487 
génocide arménien et son rapport avec la shoah. L'A. consacre quelques pages, dans sa conclusion, au rapprochement comparatif, entre la «déportation » des Arméniens et celle des juifs en 1941, mettant en accusation au passage les Grandes Puissances, qui ont entériné l'État national unitaire turc au traité de Lausanne, sans même autoriser le nécessaire travail de deuil et de mémoire sur la tragédie arménienne. On l'aura compris, H.-L.K. s'est forgé une intime conviction, qu'il défend avec une persuasion militante. Mais sa rigueur méthodologique évite d'asséner des vérités indiscutables. Elle invite au débat, et ouvre à plusieurs reprises de nouvelles pistes de recherche, pour une histoire qui reste encore pour beaucoup dans la pénombre.

\section{Bernard Heyberger.}

116.29

LUBAC (cardinal Henri de).

La Rencontre du bouddhisme et de l'Occident. Paris, Cerf, 2000, 350 p., (traductions, errata, glossaire, index) (in Oeuvres complètes, XXII, Sixième section).

Il convient de saluer l'initiative de l'Association Internationale Cardinal Henri de Lubac et des éditions du Cerf de publier les œuvres complètes de l'un des plus grands penseurs catholiques du $\mathrm{XX}^{\mathrm{e}}$ siècle. Répartis en douze sections, les cinquante volumes prévus sont édités sous la direction scientifique de Georges Chantraine et Michel Sales, assistés de Fabienne Clinquart. Parmi les premières livraisons, La rencontre du bouddhisme et de l'Occident, publié en 1952, est déjà passé à la postérité comme un ouvrage pionnier en un domaine, celui de la rencontre Orient/Occident, qui ne cesse de prendre de l'importance au fil des décennies.

Appelé à enseigner l'histoire des religions à la faculté catholique de Lyon dès 1929, le Père de Lubac s'est intéressé de très près au bouddhisme, qu'il considérait comme un « fait spirituel » majeur. Après la guerre, il publiera trois ouvrages sur le bouddhisme et sa confrontation avec l'Occident chrétien : Aspect du bouddhisme (1951), La rencontre du bouddhisme et de l'Occident (1952) et Amida (1955). De ces trois livres, celui qui aura la plus grande influence sur la communauté intellectuelle et scientifique est sans conteste La rencontre... et on ne peut que se réjouir de la réédition d'un livre qui n'a rien perdu de son intérêt et qui était malheureusement épuisé depuis longtemps.
Divisé en cinq grands chapitres, l'ouvrage reconstitue les principales étapes de la découverte du bouddhisme par les Occidentaux : Antiquité et Moyen-Âge ; la découverte missionnaire ; la découverte scientifique ; les premières controverses; progrès scientifiques et positions spirituelles. Près de cinquante ans après sa publication, on peut constater que ce formidable travail d'érudition n'a pas pris une ride. Ses points forts sont assurément la période missionnaire, la naissance des études bouddhiques en Occident et les controverses du XIX siècle autour de la confrontation du bouddhisme et du christianisme. Tout juste peut-on déplorer deux faiblesses dans cet exposé fouillé et lumineux. Le Père de Lubac accorde assez peu de place à la récupération du bouddhisme par les cercles ésotériques de la fin du XIX ${ }^{\mathrm{e}}$ et du début du $\mathrm{XX}^{\mathrm{e}}$ siècle. Or la naissance de ce « bouddhisme ésotérique » est au cœur de la problématique de cette rencontre, avec tous les malentendus qui en découlent, et connaîtra une formidable postérité jusqu'à nos jours. On peut aussi regretter qu'il n'ait pas davantage saisi l'importance de la confusion qui s'est opérée vers les années 1860-1880 du XIX ${ }^{\mathrm{e}}$ siècle entre la pensée de Schopenhauer et celle du Bouddha et qui contribua grandement à donner du bouddhisme en Europe une image de pensée pessimiste et de culte du vide. Ces lacunes ne diminuent toutefois en rien l'extraordinaire mérite de cette étude qui demeure irremplaçable.

On sera plus critique sur la conclusion de l'auteur, intitulée: «Le bouddhisme et la pensée européenne ». Dans la fin de cette longue conclusion, le savant jésuite change soudainement de ton, quitte ses habits d'historien distancié et porte un regard chrétien assez critique sur le bouddhisme. Même s'il lui reconnaît d'indéniables qualités, il condamne avec fermeté ceux qui délaissent les trésors de la tradition chrétienne pour s'intéresser au bouddhisme et juge même cette «entreprise insensée », comme « la plus folle des folies » (p. 279). Outre le caractère polémique et apologétique de ces propos, il apparaît surtout que 1'A. est encore tributaire d'une lecture erronée $\mathrm{du}$ bouddhisme, compris comme un culte du vide et du néant. Nul théologien sérieux n'oserait aujourd'hui porter de tels jugements. Certes, il y a eu depuis le Concile Vatican II de véritables progrès dans la connaissance du bouddhisme et de la diversité de ses traditions, qui rendent caducs ces jugements hérités du $\mathrm{XIX}^{\mathrm{e}}$ siècle.

On pourra évidemment aussi souligner les nombreux événements survenus depuis 1952 dans cette rencontre du bouddhisme et de 
l'Occident et qui rendent le livre de l'A. aujourd'hui incomplet. Mais nous dirions justement que ces événements (progrès fulgurant des études bouddhiques, installation de divers courants bouddhistes en Europe et aux États-Unis, conversions au bouddhisme de nombreux occidentaux, naissance du dialogue juif/chrétien-bouddhiste etc.) donnent, avec du recul, plus de force encore à l'intuition du Père de Lubac qui avait admirablement pressenti l'importance de cette rencontre. Signalons à ce sujet l'excellente contribution de Jacques Scheuer («cinquante ans plus tard: la rencontre du bouddhisme et de l'Occident depuis Henri de Lubac ») au colloque du 11 novembre 2000 à la Fondation Singer-Polignac, dont les Actes viennent d'être publiés au Cerf sous la direction de Paul Magnin (L'intelligence de la rencontre du bouddhisme, Études lubaciennes, II, 2001, 208 p.)

Frédéric Lenoir.

\subsection{MILTON-EDWARDS (Beverley).}

Islamic Politics in Palestine. Londres-New York, I.B. Tauris publishers, 1996, 256 p. (bibliogr., index).

Cet ouvrage décrit le développement de l'islamisme en Palestine depuis les années 1920. L'auteur construit l'histoire politique des groupes se réclamant de l'islam et montre leur diversité : ils ne sont pas toujours liés au problème de la colonisation, du conflit avec Israël après 1948, ou à la construction d'un État Palestinien. Certains d'entre eux sont des mouvements piétistes, d'autres ont recours à la lutte armée. Cet historique se fonde sur une enquête ethnographique faite à partir d'une cinquantaine d'entretiens et d'observations de terrain ainsi que sur une documentation de première main. D'une grande clarté dans son organisation, il offre des pistes de réflexion intéressantes sur la relation entre l'islam, l'idée de nation, et l'état de guerre.

L'A. met en avant la position toute particulière de la Palestine dans le phénomène plus général de la résurgence islamique qui, au Moyen-Orient, aurait été initié suite à la défaite des pays arabes face à Israël en 1967. L'A. montre que, suite à l'occupation de 1967 de Gaza et de la Cisjordanie, c'est plutôt un fort sentiment nationaliste et séculariste qui se développe, une idéologie politique où la vision d'une nation à venir est fondée sur un État multiconfessionnel qui engloberait les trois religions du Livre. Ce n'est qu'au milieu des années 1970 que l'islamisme commence lentement à se développer pour former au milieu des années
1980 un fondement idéologique au nationalisme palestinien, avec, selon l'A., dix ans de retard sur le reste du Moyen-Orient. Ce n'est donc pas l'échec du nationalisme séculariste et pro-arabe qui explique l'islamisme, mais la situation exacerbée de conflit entre les Palestiniens et l'État d'Israël. La résurgence religieuse est donc ici à relier à l'état de guerre et à l'occupation, plutôt qu'à l'échec de la construction nationale par les élites sécularistes comme cela est expliqué généralement pour décrire l'islamisation des pays arabes depuis la fin des années 1960. Si l'on prolonge le raisonnement, on peut cependant remarquer, pour nuancer la thèse de l'A., que dans les cas de la Palestine comme du reste du monde arabe, la résurgence religieuse est toujours liée à une redéfinition du nationalisme, que l'État soit à construire comme en Palestine, ou déjà mis en place comme dans le reste du Moyen-Orient.

Organisant son ouvrage chronologiquement, l'A. décrit dans un premier temps l'itinéraire et l'idéologie de deux leaders islamiques qui furent les deux représentants les plus importants de l'islam en Palestine dans la première moitié du XX ${ }^{\mathrm{e}}$ siècle: Sheikh Izz al-Din al-Qassam, (1882-1935), leader du mouvement salafiste en Palestine, "chef-brigand " qui attira nombre de paysans et de masses pauvres au nom de l'islam, et Haj al-Amin al-Husseini, Mufti de Jérusalem à partir de 1921.

Sheikh Izz al-Din al-Qassam, formé à l'université égyptienne d'al-Azhar, s'est nourri des idées de l'islam réformiste et salafiste et s'est opposé à l'islam institutionnel du Mufti et des oulémas en général. Son discours est anticolonialiste et anti-sioniste. Son programme : établir un État islamique par le jihad armé. Son nom sera par la suite repris pour désigner l'aile armée du mouvement Hamas. Ayant organisé un petit groupe d'activistes, il est assassiné par la police britannique en 1935 et devient un martyr que les nationalistes sécularistes comme les islamistes récupèreront après 1967. Le Mufti de Jérusalem représente en revanche l'islam institutionnel, et surtout les grandes familles palestiniennes qui, par leurs rivalités constantes au sein d'un système clientéliste, signent le déclin irrémédiable des oulémas. Les deux figures religieuses décrites par l'A. ne représentent plus aucune force politique réelle au moment de la création d'Israël en 1948.

L'A. éclaire ensuite rapidement l'évolution de l'islam politique après 1948 sous administration égyptienne, jordanienne et israélienne. Après 1948, on est dans un contexte de défaite militaire: la société palestinienne s'est en quelque sorte désintégrée, le leadership politique palestinien est quasiment absent. Il faut 